\title{
DANDY-WALKER SYNDROME; \\ CLINICAL ANALYSIS AND SURGICAL OUTCOME
}

1. Resident Medical Officer Department of Neurosurgery

Dow University of Health Sciences

Civil Hospital Karachi.

2. Post graduate Trainee

Department of Neurosurgery

Abassi Shaheed Hospital Karachi

3. Neurosurgeon

Department of Neurosurgery

Abassi Shaheed Hospital Karachi

4. House Officer

Department of Neurosurgery

Dow University of Health Sciences

Civil Hospital Karachi

Correspondence Address:

Dr. Qazi Muhammad Zeeshan

Resident Medical Officer

Department of Neurosurgery

Dow University of Health Sciences

Civil Hospital Karachi.

doctor.karachi@gmail.com

Article received on:

06/04/2016

Accepted for publication:

03/12/2016

Received after proof reading:

$18 / 01 / 2017$
Dr. Qazi Muhammad Zeeshan', Dr. Muhammad Hashim², Dr. Syed Mohammad Maroof Hashmi ${ }^{3}$, Dr. Mohammad Absar Anwar ${ }^{4}$

ABSTRACT... Introduction: Dandy-Walker Malformation is an inborn condition that includes the triumvirate of cystic enlargement of the fourth ventricle, posterior fossa distension with rise of the tentorium and agenesis of cerebellar vermis. The purpose of this study is to determine the Clinical presentation and associated complications, mortality and morbidity of patient undergoing placement of shunt with $\mathrm{Y}$ - connector in Dandy Walker Malformation. Study Design: Case Series comprised of 85 cases. Setting: Neurosurgery Ward of Tertiary Care Hospital in Karachi. Period: February 2011 to December 2015. Methodology: All patients who were presented in OPD with complaints reminiscent of DWM with accompanied Hydrocephalus and then underwent CT scan Brain without contrast to confirm the diagnosis were admitted. The patients who have previous history of operation and other co-morbid anomalies were omitted. These patients undergo drainage of Ventricular system and Posterior Fossa cyst was done mutually via Dual Shunt including Ventricular-peritoneal and Cysto-peritoneal shunt with $Y$ connector. There were few complications and mortality after this surgical intervention which was noted for a month. All records were recorded and evaluated by SPSS v.20. Result: A vast majority of patients included were Female. The average age of patients was 2.5 years +/- 1 Standard Deviation. The chief complaint was Hydrocephalus, existing in all patients, after that cerebellar signs in $55(64.7 \%)$ and other signs in $10(11.8 \%)$ patients. Others signs includes; milestones were delayed, atypical gait and few patients were suffered from psychiatric problems. Complications which were observed were shunt; Fracture/Dislocation in $10(11.8 \%)$, shunt blockage in $8(9.4 \%)$, malpositioning is also $8(9.4 \%)$, Intracranial Hemorrhage in 7 (8.24\%) patients and Infection in $10(11.8 \%)$. These complications were observed within a month of surgery. Unfortunately, two $(2.35 \%)$ patient were also expired after surgical approach. Conclusion: It is concluded that Dandy Walker Malformation is categorized by a triumvirate. Hydrocephalus is a most common symptom and principal cause of referral to hospitals. The commonest difficulty acknowledged after shunting is Malfunction and shunt infections. The lowest mortality is related to Dual Shunt with $Y$ connector when compared to other approaches for management of shunt with Y-connector. Thus, it is found to be a worthy decision in given DWM patients.

Key words: $\quad$ Hydrocephalus, Y connector, Dandy Walker Malformation, VP Shunt, Shunt Fracture, Cysto-peritoneal Shunt.

Article Citation: Zeeshan QM, Hashim M, Hashmi SMM, Anwar MA. Dandy-walker syndrome; clinical analysis and surgical outcome. Professional Med J 2017;24(1):47-50. DOI: $10.17957 / T P M J / 17.3392$

\section{INTRODUCTION}

Dandy-Walker Malformation is an inborn condition that includes the triumvirate of cystic enlargement of the fourth ventricle, posterior fossa distension with rise of the tentorium and agenesis of cerebellar vermis. An Abundance of brain related and nonrelated problems exist, but DW is acknowledged by the overhead three characteristics. Hydrocephalus is a potential complication of this syndrome. Furthermore complicated pathogenesis with multifactorial etiologies, also Umbilical cord or placental anomalies may also be associated with its advancement. ${ }^{1}$ Dandy-Walker Malformation is clinically presaged by indication of hydrocephalus with focal neurological signs have less protuberant characteristic. ${ }^{2}$

Concerning management, there is still disagreementoverthefinestsurgicalmanagement. Previously, surgical removal of the membrane in 
the posterior fossa was routine management, but it has rising rate of difficulties and the patient with this management required additional shunting systems. ${ }^{3}$ Consequently, surgical management remains divisive, prognosis differs significantly rendering to the harshness of syndrome and related co-morbidities. In Pakistan, there is range of treatment routes consumed at different centers. Consequently, this study intended to regulate the hitches and mortality linked with shunt with $y$-connector at the study center.

\section{MATERIAL AND METHODS:}

\section{Study Design and Place of Study}

The study was a Case Series comprised of 85 cases. It was conducted in Neurosurgery Ward of a Tertiary Care Hospital of Karachi from February 2011 to December 2015.

\section{Inclusion Criteria}

All patients who were presented in OPD with complaints reminiscent of DWM with accompanied Hydrocephalus and then underwent CT scan Brain without contrast to confirm the diagnosis were admitted.

\section{Exclusion Criteria}

All patients who have previous history of operation and other co-morbid anomalies were omitted.
These patients undergo drainage of Ventricular system and Posterior Fossa cyst was done mutually via Dual Shunt including Ventricularperitoneal and Cysto-peritoneal shunt with $Y$ connector. There were few complications and mortality after this surgical intervention which was noted for a month. Numerical variable were showed in Mean and Standard Deviation and Categorical variable were presented in Frequencies and Percentages. All records were recorded and evaluated by SPSS v.20.

\section{RESULT}

A vast majority of patients included were Female. The average age of patients was 2.5 years +/1 Standard Deviation. The chief complaint was Hydrocephalus, existing in all patients, after that cerebellar signs in 55 (64.7\%) and other signs in $10(11.8 \%)$ patients. Others signs includes; milestones were delayed, atypical gait and few patients were suffered from psychiatric problems. Complications which were observed were shunt; Fracture/Dislocation in 10 (11.8\%), shunt blockage in $8(9.4 \%)$, malpositioning is also 8 (9.4\%), Intracranial Hemorrhage in 7 (8.24\%) patients and Infection in 10 (11.8\%). These complications were observed within a month of surgery. Unfortunately, two (2.35\%) patient were also expired after surgical approach (Table I).

\begin{tabular}{|c|c|c|c|c|c|}
\hline $\begin{array}{c}\text { Mal- } \\
\text { positioning }\end{array}$ & $\begin{array}{c}\text { Shunt: Fracture/ } \\
\text { Dislocation }\end{array}$ & $\begin{array}{c}\text { Intracranial } \\
\text { Hemorrhage }\end{array}$ & Infection & Shunt Blockage & Mortality \\
\hline $8(9.4 \%)$ & $10(11.8 \%)$, & $7(8.24 \%)$ & $10(11.8 \%)$, & $8(9.4 \%)$ \\
\hline & Table-I. Complications after placement of Shunt with Y connector $(\mathrm{n}=85)$ \\
\hline
\end{tabular}

\section{DISCUSSION}

DWM is an infrequent disease. It has complex pathogenesis with multifactorial etiologies. The major Symptom and subsequent complication is Hydrocephalus. ${ }^{6}$ The patients has Supplementary focal neurological symptoms due to agenesis of cerebellum but they are frequently overlooked by the patients as replicated in this study. Though, these patients possibly will also present with other non-CNS defects. ${ }^{7,8}$

Cerebellum plays a vital role in motor and cognition skills. Thus, the result of this disorder on intellectual growth is capricious, with some children having standard cognition and others under no circumstances attaining standard cerebral improvement. ${ }^{9}$ Additional austere intellectual damage has been perceived in patients with agenesis of the corpus callosum. ${ }^{10}$ This study presented that in small group of patients explanations for pursuing medical advice were milestones delay, Psychological issues, petulance, and strange gait. The parents usually disregard these symptoms until these hindered the daily routines. 
Extensively swerving views on the finest therapy for intracranial cerebrospinal fluid cysts, especially on the arachnoid cysts and the DWM. Membrane removal for management was originally suggested by Dandy. It has high failure rate. This therapy was grounded on an supposition that the enlargement of the fourth ventricle and SupraTentorial hydrocephalus is due to the blocked passages of the fourth ventricle. ${ }^{11}$ This process is disregarded because of a high rate of mortality $10 \%$ and a failure rate of $70 \% .^{12}$ Also, Udvarhelyi and Epstein still support this management by method of removal of cyst wall in children aged over 3 years. ${ }^{13}$ It was later substituted by shunting due to high morbidity and mortality related to excision. ${ }^{14}$ Since, Transtentorial herniation of cyst or expansion has been noted following settlement of ventricular shunt unaided, which is related with high death. Hence, Kumar et al. support shunting both of cyst and ventricles. ${ }^{15}$ The present familiarity with this procedure exhibited a very low mortality rate (2.35\%).

Shunt system has conjoint problems of failure and infection. Added impediments included focal cranial nerve deficits and headaches subsequent infection instigated by a cysto peritoneal shunt due to securing of the brainstem. ${ }^{10} \mathrm{~A}$ singlecatheter shunting system efficiently drained the supratentorial and infratentorial sections has been found to be linked with abridged difficulty and possible risk allied with the shared shunting systems necessary by so many with DWM related hydrocephalus. ${ }^{17}$ The current results harmonized with other studies in a way that shunt failure being the main problems in these patients with dual shunt with $y$-connector heading to a single channel for drainage.

Endoscopic and stereotactic procedures have extended the available treatment potentials for posterior fossa cysts. Endoscopic approaches of trans-aqueductal settlement of a single-catheter cyst-ventriculoperitoneal shunt have also been observed to be with decent outcomes. ${ }^{19}$ Effective endoscopic third ventriculostomy caused a small lessening in ventricle size and changing degrees of decrease in size of cyst. ${ }^{20}$ It is also distinguished that failure rates of third ventriculostomy are stated to be chiefly great in the first year of age 22,23 .

\section{CONCLUSION}

It is concluded that Dandy Walker Malformation is categorized by a triumvirate. Hydrocephalus is a most common symptom and principal cause of referral to hospitals. The commonest difficulty acknowledged after shunting is Malfunction and shunt infections. The lowest mortality is related to Dual Shunt with $Y$ connector when compared to other approaches for management of shunt with Y-connector. Thus, it is found to be a worthy decision in given DWM patients.

Copyright (C) 03 Dec, 2016.

\section{REFERENCES}

1. Zhang $X B, G u Y Q$, Sun $X F$, Wang $Y N$, Wang $A C$. DandyWalker complex: a clinicopathologic study of 9 cases. Zhonghua Bing Li Xue Za Zhi 2013; 42:815-8.

2. Osenbach RK, Menezes AH. Diagnosis and management of the Dandy-Walker malformation: 30 years of experience. Pediatr Neurosurg 1992; 18:17989.

3. Hu CF, Fan HC, Chang CF, Wang CC, Chen SJ. Successful treatment of Dandy-Walker syndrome by endoscopic third ventriculostomy in a 6-month-old girl with progressive hydrocephalus: a case report and literature review. Pediatr Neonatol 2011; 52:42-5.

4. George A. Alexiou. Dandy-Walker malformation: analysis of 19 cases. J Child Neurol 2010; 25:188-9.

5. Cedzich C, Lunkenheimer A, Baier G, Müller J, Kühner A. Ultrasound-guided puncture of a Dandy-Walker cyst via the lateral and III ventricles. Childs Nerv Syst 1999; 15:472-6.

6. Rizvi R. Hydrocephalus in children. JPMA 2005: 55:502- 7 .

7. Hussain Z, Masroor I, Haider Q, Alam T. Goldston syndrome. J Coll Physicians Surg Pak 2011; 21:2434.

8. CholY, Hwang SK, Kim SH. Dandy-Walker malformation associated with neurocutaneous melanosis. Korean Neurosurg Soc 2011; 50:475-7.

9. Halgren C, Kjaergaard S, Bak M, Hansen C, El-Schich Z, Anderson $\mathrm{CM}$, et al. Corpus callosum abnormalities, intellectual disability, speech impairment, and autism 
in patients with haploinsufficiency of ARID1B. Clin Genet 2012; 82: 248-55.

10. Liu JC, Ciacci JD, George TM. Brainstem tethering in DandyWalker syndrome: a complication of cystoperitoneal shunting. Case report. J Neurosurg 1995; 83:1072-4.

11. Domingo Z, Peter J. Midline developmental abnormalities of the posterior fossa: correlation of classification with outcome. Pediatr Neurosurg 1996; 24:11-118.

12. Dandy WE, Blackfan KD. Internal hydrocephalus. An experimental, clinical and pathological study. Am J Dis Child 1914; 3:406-82.

13. Tadakamadla J, Kumar S, Mamatha GP. Dandy-Walker malformation: an incidental finding. Indian $\mathrm{J}$ Hum Genet 2010; 16:33-5.

14. Serlo W, Wendt LV, Heikkinen E, Saukkonen AL, Nystorm St. Shunting procedures in the management of intracranial cerebrospinal fluid cysts in infancy and childhood. Acta Neurochirugica 1985; 76:111-6.

15. Kumar R, Jain MJ, Chhabra DK. Dandy-Walker syndrome: different modalities of treatment and outcome in 42 cases. Child's Nerv Syst 2001; 17:34852.

16. Mandiwanza T, Kaliaperumal C, Caird J. Central brain herniation in shunted Dandy-Walker cyst. Childs Nerv Syst 2013; 29:1035-8.

17. Sikorski CW, Curry DJ. Endoscopic, singlecatheter treatment of Dandy-Walker syndrome hydrocephalus: technical case report and review of treatment options. Pediatr Neurosurg 2005; 41:264-8.

18. Spennato $P$, Mirone G, Nastro A, Buonocore MC, Ruggiero $C$, Trischitta $V$, et al. Hydrocephalus in Dandy-Walker malformation. Childs Nerv Syst 2011; 27:1665-81.

19. Turner MS, Nguyen HS, Payner TD, Cohen-Gadol AA. A novel method for stereotactic, endoscope-assisted transtentorial placement of a shunt catheter into symptomatic posterior fossa cysts. J Neurosurg Pediatr 2011; 8:15-21.

20. Mohanty A, Biswas A, Satish S, Praharaj SS, Sastry KV. Treatment options for Dandy-Walker malformation. J Neurosurg 2006; 105:348-56.

21. Mandiwanza T, Kaliaperumal C. Authors' response to letter to the editor "Central brain herniation in DandyWalker syndrome”. Childs Nerv Syst 2013; 29:1791.

22. Morigaki R, Pooh KH, Nakagawa Y. Endoscopic transaqueductal placement of a single-catheter cystventriculoperitoneal shunt in a neonate with DandyWalker malformation-associated hydrocephalus: case report. Neurol Med Chir (Tokyo) 2011; 51:256-9.

23. Koch-Wiewrodt $D$, Wagner W. Success and failure of endoscopic third ventriculostomy in young infants: are there different age distributions? Childs Nerv Syst 2006; 22:1537-41.

24. Marinov M, Gabrovsky S, Undjian S. The Dandy-Walker syndrome: diagnostic and surgical considerations. Br J Neurosurg 1991; 5:475-83.

\section{AUTHORSHIP AND CONTRIBUTION DECLARATION}

\begin{tabular}{|c|l|l|l|}
\hline Sr. \# & \multicolumn{1}{|c|}{ Author-s Full Name } & \multicolumn{1}{|c|}{ Contribution to the paper } & Author=s Signature \\
\hline 1 & Dr. Qazi M. Zeeshan & $\begin{array}{l}\text { Concept writeup layout } \\
\text { analysis } \\
\text { Write up data collection } \\
\text { analysis } \\
\text { Write up concept data } \\
\text { collection } \\
\text { Data entry statistical } \\
\text { analysis }\end{array}$ \\
\hline 4 & Dr. Muhammad Hashim & Dr. Syed M. Maroof Hashmi \\
\hline
\end{tabular}

